\title{
Kritiese denke as opvoedkundige imperatief
}

Pieter van Veuren

Departement Filosofie

Randse Afrikaanse Universiteit

JOHANNESBURG

\begin{abstract}
The purpose of this paper is to stimulate debate on the teaching of thinking skills in and across the university curriculum. Because RAU includes instruction in critical and creative thinking skills as an educational requirement in its mission statement, I take issue with this university's mission statement and argue that the teaching of thinking skills is a useless endeavour unless it is done within the framework of a critical thinking approach: such an approach focuses on the affective dispositions or virtues which motivale the use of thinking skills in concrete situations, and articulates worthwhile goals for the use of thinking skills. In conclusion I focus attention on some of the points in the discussion which seem to merit further research and debate.
\end{abstract}

\section{Inleiding}

Die Randse Afrikaanse Universiteit se "missie in die besonder" verbind die Universiteit tot die kweek van kritiese en kreatiewe denkvaardighede by studente. 1 Deurdat "kritiese en kreatiewe denkvaardighede" as opvoedkundige doelstelling gestel word in die Universiteit se missiestelling, bevind RAU hom in die geselskap van toonaangewende universiteite in die VSA, Engeland en Europa. Maar die Universiteit onttrek hom myns insiens uit hierdie goeie geselskap as dit kom by ' $n$ voortgaande debat oor "kritiese en kreatiewe denkvaardighede" in die algemeen, of geïnkorporeer in al die dissiplines wat aan die Universiteit gedoseer word. Wat hieronder volg, het as doel om so 'n debat te stimuleer.

* Ek wil in die eerste plek beweer dat dit nou, meer as ooit tevore, nodig is om oor die frase "kritiese en kreatiewe denkvaardighede" in die missiestelling te besin en onder andere die volgende vrae te stel: watter kritiese en kreatiewe

1 Dié parafrase kom uit die missiestelling van September 1989: "Die RAU lê hom in die besonder daarop toe om: .. 3.2 by studente kritiese en kreatiewe denkvaardighede te kweek ..." 
denkvaardighede is ter sake? Watter doelstellings word nagestreef in die onderrig van kritiese en kreatiewe denkvaardighede? Kan sulke vaardighede betroubaar getoets word?

* In die tweede plek wil ek die manier waarop die item "kritiese en kreatiewe denkvaardighede" in die missiestelling aan die orde gestel word, krities ondersoek deur te vra na die aannames wat dit onderlê en die implikasies wat daaruit afgelees kan word. In hierdie verband sal ek betoog dat onderrig in "denkvaardighede" in die breër konteks van kritiese denke behoort te geskied.

* Ek wil in die derde plek op grond van oorweginge wat onder die eerste twee punte genoem sal word, konkludeer dat daar aan die item kritiese en kreatiewe denkvaardighede ' $\mathrm{n}$ gewysigde formulering gegee moet word in die besondere missiestelling van die Universiteit, en dat dit sterker as 'n doelstelling geïnterpreteer moet word, naamlik as 'n opvoedkundige imperatief.

\section{Kontekstualisering}

Aangesien missiestellings uit die aard van die saak neig om kort en kragtig te wees, is dit nodig om sulke stellings te kontekstualiseer ten einde hulle relevansie vir ' $n$ bepaalde tyd te bepaal. Kontekstualisering kom neer op ' $n$ rekonstruksie van die agtergrond waarteen die geformuleerde doelstellings gesien en uitgevoer moet word.

Die breedste agtergrond vir die betrokke missiestelling is die wêreld waarin die universiteit sy studente uitstuur nadat hulle hul studies voltooi het. Hierdie wêreld impliseer in die negentigerjare 'n wêreld wat gekenmerk word deur makroprobleme waarvoor daar nie simplistiese oplossings is nie. Hierdie probleme is welbekend uit die hedendaagse koerantberigte en tydskrifartikels: besoedeling en soms vernietiging van die milieu, verstedeliking, oorbevolking, onstabiele en soms baie antagonistiese menseverhoudinge, ideologiese konflik en krimpende hulpbronne.

Wanneer studente die universiteit verlaat, betree hulle die arbeidsmark. Laasgenoemde is ook ' $n$ agtergrond waarteen die betrokke missiestelling gesien kan word. Teen die agtergrond van die arbeidsmark word die verwysing na kritiese en kreatiewe denkvaardighede in die missiestelling besonder betekenisvol, want die hedendaagse arbeidsmark word gekenmerk deur 'n aantal unieke tendense.

* Die afgelope dekade het die produksie, evaluering en verspreiding van inligting 'n "growth industry" geword waarby al hoe meer mense betrokke is (Lyotard, 1984:3-6). Hierdie 'inligting-rewolusie' werk ook terug op die produksieproses. Hantering en evaluering van inligting is nie meer funksies 
wat beperk is tot die bestuur van 'n onderneming nie: werkers op verskillende vlakke moet die vermoë hê om inligting te analiseer, te evalueer en besluitnemingsprosesse uit te voer sodat produksieprosesse meer doeltreffend kan verloop.

* Werknemers kry meer verantwoordelikheid deurdat 'n deel van die bestuurstake op alle vlakke aan hulle oorgedra word. In hierdie situasie word van 'n werknemer vereis om meer as een taak te hanteer en om krities en kreatief te dink oor waarmee hy of sy besig is: "asking questions, challenging assumptions are becoming part of everyone's job" (Toffler, 1990:211). Kritiese, kreatiewe en besluitnemingsdenke het in 'n groot deel van Suid-Afrika se 'Eerstewêreldekonomie' self produksiefaktore geword en daarom gaan dit vir werknemers in hierdie sektor nie soseer om "working for a living" nie maar om "thinking for a living" (Paul, 1992:34).

Teen hierdie agtergrond is dit duidelik dat dit dringend nodig geword het om te besin oor onder andere die volgende vrae:

* Wat word presies verstaan onder "kritiese en kreatiewe denkvaardighede"?

* Watter kritiese en kreatiewe denkvaardighede is relevant vir die hedendaagse wêreld en arbeidsituasie?

* Gaan dit om algemene kritiese en kreatiewe denkvaardighede of om vaardighede wat dissipline-spesifiek is, of om albei?

* Het kritiese denke 'n etiese dimensie of is dit eties neutraal?

* Hoe kan kritiese en kreatiewe denkvaardighede sistematies en deurlopend aan studente onderrig word? Watter implikasies sal dit hê vir kursusontwerp of herontwerp, personeelopleiding, ensovoorts?

* Watter breër doelstellings word nagestreef deur die onderrig van kritiese en kreatiewe denkvaardighede?

* Wat is die opvoedkundige voorwaardes vir die suksesvolle onderrig van kritiese denke?

* Kan kritiese en kreatiewe denkvaardighede betroubaar getoets word?

Die vrae hierbo word geformuleer as kempunte van ondersoek en debat. In die volgende afdelings sal slegs die probleme wat in die eerste en die laaste drie vrae aan die orde gestel word, verdere aandag kry.

\section{Kritiese denke}

Die probleme wat hierbo aan die orde gestel is, is reeds sedert die begin van die tagtigerjare die onderwerp van ondersoek en akademiese debat in die VSA, Kanada en in Nederland. Wanneer vanuit die agtergrond van hierdie debat 
Kritiese denke as opvoedkundige imperatief

krities-evaluerend gekyk word na die manier waarop die item "kritiese en kreatiewe denkvaardighede" in die missiestelling van RAU aan die orde gestel word, val dit op dat alleen "denkvaardighede" genoem word. Die debat waarna hierbo verwys is, het reeds in sy beginjare verby blote "denkvaardighede" beweeg na 'n meer verantwoorde konsepsie van kritiese denke (critical thinking) wat méér as "denkvaardighede" omvat. Die kweek van denkvaardighede alleen by studente is 'n gekortwiekte opvoedkundige program (Lipman, 1989:4). Die kweek van denkvaardighede by studente waarborg nie dat hulle (hoe ook al) uitgeoefen sal word nie: studente moet ten minste ook die affektiewe disposisie of gewoonte hê om denkvaardighede te beoefen. Op grond van hierdie oorweginge word denkvaardighede nie in isolasie onderrig nie, maar in die konteks van kritiese denke. 'Kritiese denke' is ' $\mathrm{n}$ benadering wat die spesifiek logiese vaardighede (analise, evaluering, inferensie, ensovoorts) beskou as mikrovaardighede wat slegs in makrovaardighede (soos die vaardigheid om 'n essay te skryf, die vaardigheid om 'n boek te lees, om met begrip na 'n lesing te luister) effektief bruikbaar is. Behalwe die klem wat geplaas word op affektiewe disposisies, is dit verder kenmerkend van hierdie benadering dat geen skeiding gemaak word tussen kritiese en kreatiewe denke nie (Oxman-Michelli, 1991(b): 1).

Daar bestaan 'n redelike groot mate van konsensus dat kritiese denke in terme van denkvaardighede (makro en mikro) en disposisies omskryf kan word (Facione, 1990:3). Ek sal vervolgens 'n lys gee van wat allerweë beskou word as die belangrikste mikrovaardighede en die kerndisposisies wat die 'kritiese denker' behoort te hê. ${ }^{2}$

\subsection{Denkvaardighede}

Onder 'denkvaardighede' word verstaan die paraatheid van 'n kognitiewe vermoë om in werking te tree, en behendigheid in die gebruik daarvan in uiteenlopende kontekste of situasies. Sentrale denkvaardighede is onder andere interpretasie, analise, evaluasie, inferensie, verklaring en selfregulering.

* Interpretasie omvat vaardighede soos die klassifisering van inligting, dit wil sê kategorisering, formulering van raaıwerke vir die verstaan, beskrywing of karakterisering van inligting. Interpretasie kan ook beteken om die betekenis van onder andere woorde, konsepte, stellings, tekens en gedrag deur parafrasering, stipulering, beskrywing of figuurlike middele (metafoor, analogie, en so meer) te verhelder.

2 Ek neem hierdie gegewens met kleiner wysigings en byvoegings oor uit Facione (1990:13-19). 
* Analise in die konteks van denkvaardighede het veral betrekking op die vaardigheid om argumente te identifiseer, on te differensieer tussen die premis(se) en konklusie van 'n argument, en om die versweë aannames en implikasies van 'n argument korrek te identifiseer.

* Evaluering sluit onder andere in die identifisering van relevante faktore wat betrekking het op die aanneemlikheid van 'n bewering. (Byvoorbeeld: om die faktore te identifiseer wat 'n persoon 'n geloofwaardige getuie maak van 'n sekere gebeurtenis, of van 'n persoon 'n geloofwaardige outoriteit maak op ' $n$ bepaalde gebied.) Evaluering van argumente kom onder andere neer op ' $n$ oordeel of die premis(se) van die argument die konklusie noodwendig waar maak (deduksie), of slegs waarskynlik waar maak (induksie), en om te oordeel of ' $n$ argument op valse of betwyfelbare vooronderstellings berus, of moontlik onaanvaarbare konsekwensies het (Van Veuren, 1991:41).

* Inferensie is, algemeen gestel, die vermoë om aanneemlike konklusies uit premisse af te lei, om hipoteses te formuleer, en om die implikasies van data uit te spin. In die besonder kom dit neer op die vernoë om raak te sien watter soort ondersteuning premisse nodig het, en om 'n strategie te ontwerp om inligting te versamel om die nodige ondersteuning te voorsien; om verskillende alternatiewe oplossings vir 'n probleem te formuleer; om alternatiewe hipoteses oor 'n gebeurtenis te projekteer; om verskillende planne te ontwikkel om 'n doelstelling te bereik.

* Verklaring is die vermoë om onder andere jou navorsingsresultate helder en duidelik te stel; om jou navorsingsprosedures te beskryf en te regverdig (byvoorbeeld om jou keuse van ' $n$ besondere statistiese toets vir die analise van data aanneemlik te maak); om moontlike besware teen jou metode, konseptualiseringe en argumente te antisipeer en die hoof te bied.

* Selfregulering is die vermoë om eksplisiet na te dink oor jou eie redenering en die kognitiewe vaardighede wat daarby betrokke is; om krities te kan oordeel oor jou eie stereotipes, vooroordele, waardes en motiveringe; om so billik, deeglik en redelik as moontlik te wees in jou interpretasies, inferensies en verklarings, en om waar nodig selfkorreksie toe te pas.

\subsection{Kerndisposisies of 'denkgewoontes'}

Denkvaardighede korreleer met disposisies om die vaardighede te beofen: kritiese denkvaardighede tree eers dán in werking as daar ook die dryfvere of motivering by mense aanwesig is om onder andere rasioneel, ondersoekend, ontdekkend en ordelik te dink. Sonder die 'affektiewe' dimensie word kritiese denke nie tot ' $\mathrm{n}$ gewoonte nie en word denkvaardighede onreëlmatig aangewend of glad 


\section{- Kritiese denke as opvoedkundige imperatief}

nie aangewend buite die onderrigsituasie nie. Alhoewel die meer tegniese denkvaardighede relatief vimnig aangeleer kan word, neem dit tyd om denkgewoontes te vestig omdat hulle deel uitmaak van mense se persoonlike ontwikkeling en groei tot volwassenheid.

Die kerndisposisies wat bevorderlik is vir kritiese denke kan in twee groepe verdeel word: algemene lewensbenaderings of houdings, en meer spesifieke denkgewoontes wat in die akademiese konteks relevant is (Facione, 1990:25).

\section{Algemene lewenshenaderings}

- Weetgierigheid met betrekking tot 'n breë spektrum onderwerpe; die strewe oin goed ingelig te wees

- Selfvertroue in jou eie redeneervermoë

- Oopheid teenoor sienings/standpunte/beskouings wat vall jou eie verskil; begrip vir en buigsaamheid in die oorweging van alternatiewe sienings/opsies.

- Billikheid in die beoordeling van ander se opinies, argumente, beskouings

- Eerlikheid oor jou eie sydighede, vooroordele, ego- en sosiosentriese neigings.

- Bereidheid om jou oordeel op te skort, bereidheid tot selfkorreksie, bereidheid tot korreksie deur ander mense

\section{Spesifieke denkgewoontes}

- $\quad$ 'n Strewe na helderheid in die formulering van stellings of vrae

- $\quad$ 'n Strewe na ordelikheid en logiese samehang.

- Ywerigheid in die soek van inligting, versameling van data.

- Tersaaklikheid in die voorlegging van argumente, bewyse, ondersteunende materiaal.

- Deursettingsvermoë wanneer moeilikhede opduik.

- Redelikheid in die seleksie en toepassing van kriteria.

- Oplettendheid vir geleentheide om kritiese denkvaardighede toe te pas

\section{Oorkoepelende doelstellings}

RAU se besondere missiestelling on "by studente kritiese en kreatiewe denkvaardighede te kweek" staan in die konteks van 'n algemene missiestelling wat te kenne gee dat opleiding in die vaardighede van kritiese denke en die vestiging van goeie denkgewoontes by studente nie 'n doel op sigself is nie: dit gaan 
volgens die Universiteit se leuse om "diens deur kennis". Dié leuse formuleer 'n oorkoepelende doelstelling wat soos volg gespesifiseer kan word met die oog op kritiese denke:

* Om studente op te lei tot selfstandigheid in rasionele denke. Dit gaan nie om opleiding in 'hoe om te dink' in ' $n$ absolute sin nie, maar om opleiding in hoe om meer doeltreffend, meer krities, meer samehangend en steekhoudend en meer kreatief te dink as wat mense gewoonlik doen.

* Om studente te lei en te motiveer om sulke kritiese denke van toepassing te maak in hulle studie en in hulle lewens as lede van 'n arbeidsgemeenskap en politieke gemeenskap sodat hulle hulle studiegeleenthede en werksgeleenthede optimaal kan benut, oorwoë oordele kan maak oor openbare sake, en kan bydra tot die demnokratiese oplossing van probleme.

\section{Opvoedkundige voorwaardes vir suksesvolle onderrig van kritiese denke}

Onderrig in kritiese denke vereis 'n bepaalde opvoedkundige ingesteldheid en styl: dit is nie-outoritêr en niedidaktories of dit is kontraproduktief. Dit is - positief gestel - onderrig wat positief reageer op studente se versoeke om redes te gee vir bewerings wat gemaak word, verklarings te gee vir leerinhoude, en kritiese dialoog met die dosent aanmoedig. 'n Dialogiese onderrigstyl (dialoog met die dosent, tussen studente onderling) is by uitstek geskik om studente se vermoë te ontwikkel om selfstandig vrae te stel, bewyse te soek, altematiewe te oorweeg en selfkrities te dink. Kortweg: onderrig in kritiese denke veronderstel 'n bemagtigende onderrigstyl.

Aangesien onderrig in kritiese denke nie alleen die aanleer van denkvaardighede as doel het nie, maar ook bepaalde disposisies by studente wil kweek, is direkte onderrig in kritiese denke (kursusse in "Informele Logika", "Kritiese Denke" of "Praktiese Logika") alleen nie genoeg om studente tot kritiese denkers te vorm nie. Sulke kursusse het versterking dwarsdeur die kurrikulum en oor die volle termyn van studente se studie nodig. Disposisies of denkgewoontes verg tyd om hulleself te vestig en tot 'tweede natuur' te word. Om kritiese denke dwarsdeur die dissiplines te beoefen beteken dat kritiese denkvaardighede by die leer van spesifieke vakinhoude 'n rol speel (Oxman-Michelli, 1991(a):9-10), en dat navorsingsopdragte op so 'n manier beplan en geformuleer word dat kritiese denke daarin 'n rol kan speel. Sulke opdragte sal dus daarop gerig wees om studente te leer hoe om 'ekonomies', 'biologies' 'literêr-krities', 'filosofies', ensovoorts te dink, en nie om soveel moontlik 'feite', definisies, reëls, riglyne, ensovoorts te memoriseer nie. 


\section{Toetsing van denkvaardighede}

Behalwe dat toetsing motivering kan verskaf vir die onderrig van kritiese denke, is dit van groot belang vir die onderrig van kritiese denke: dit kan terugvoering oor onderrig gee wat kan lei tot verbetering van die onderrig.

Toetsing wat 'n objektiewe meting gee van studente se vermoë om denkvaardighede te hanteer, kan van belang wees vir die evaluering deur die intellektuele gemeenskap en die breër publiek van 'n inrigting soos RAU wat hom in sy missie verbind tot die 'kweek' van kritiese en kreatiewe denkvaardighede by sy studente. Toetsing kan ook vir die evaluering van studente deur werkgewers en werkgewersorganisasies van belang wees.

Daar bestaan verskillende toetse vir denkvaardighede waarvan die Cornell Critical Thinking Tests en die Watson-Glaser Critical Thinking-Appraisal die bekendste is en die meeste gebruik word (Paul \& Nosich, 1991:17).

Die hele aangeleentheid van toetsing van denkvaardighede is egter ' $n$ omstrede kwessie waaroor debat gevoer word. Daar is verskillende redes hiervoor. Dit is naamlik nie sonder meer duidelik wat presies deur toetse soos dié hierbo genoem, gemeet word nie: bestaan daar algemene denkvaardighede soos bogenoemde toetse implisiet aanvaar, of meet hulle bloot operasies wat uitgevoer word (McPeck, 1990:58)? 'n Tweede ernstige probleem is die teoriebeladenheid van begrippe soos kritiese denke en denkvaardighede: definisies van hierdie begrippe verskil en beïnvloed wat gemeet word in verskillende toetse (McPeck, 1990: 58). McPeck het myns insiens gelyk as hy sê dat evaluering van kritiese denke en denkvaardighede nie 'n 'empiriese toetsingsprobleem' sonder meer is nie (McPeck, 1990:63), en wys op die reële beperkinge van empiries-statistiese toetse.

Dit is waarskynlik juis as gevolg van dié en ander probleme met toetsing van denkvaardighede dat daar ' $n$ sterk beweging is om konsensusdefinisies van 'kritiese denke' en 'denkvaardighede' te bereik en algemeen aanvaarde toetskriteria op te stel, soos in die Amerikaners Paul en Nosich se "Proposal for the National Assessment of Higher-Order Thinking" (1991).

\section{Samevatting en debatspunte}

Aangesien dit die hoofdoel van hierdie opstel is om debat oor kritiese denke in die universiteitskurrikulum (veral by RAU) te stimuleer, sal ek in hierdie afdeling twee van die hoofpunte van die opstel weer hervat en sterk geformuleerde stellings oor hulle maak om so debat te probeer uitlok. 
Indien kritiese denke as ' $n$ opvoedkundige imperatief gesien word, is daar probleme wat dringend aandag verg. Sommige van dié probleme sal by wyse van stellings en vrae ten slotte besonderlik benadruk word vir ondersoek en debat.

By punt 2 is verwys na die sosio-ekonomiese konteks van die negentigerjare waarin 'n besondere premie gestel word op kritiese denke. Werkgewers in sektore van die arbeidsmark wat gegradueerdes in diens neem, stel in die negentigerjare eksplisiet die vereiste dat hulle voornemende werknemers nie alleen met kennis toegerus moet wees nie, maar ook met denkvaardighede. Om slegs een illustratiewe voorbeeld te noem: prof A. Andrews (direkteur van die Graduate Institute of Management and Technology) meen dat ons hele tersiêre onderrigsisteem hersien moet word sodat studente onderrig kan kry in "interpersonal skills, problem solving skills, critical thinking skills". 3

Met die sosiale en ekonomiese konteks van die negentigerjare as gegewe is dit duidelik dat onderrig in kritiese denke nie beskou kan word as 'n opsie of wenslikheid nie - dit is veel eerder 'n imperatief. Kritiese denke moet onderrig word, nie alleen as selfstandige dissipline nie, maar ook geïnorporeer in al die dissiplines van die fakulteite.

RAU se missiestelling hou wel rekening met bogenoemde imperatief. Ek het egter by punt 3 aangevoer dat die verwysing na kritiese en kreatiewe denkvaardighede in RAU se missiestelling maklik die indruk van eensydigheid kan wek, en dat om hierdie rede die formulering van hierdie item gewysig behoort te word. Die huidige formulering wat slegs van denkvaardighede melding maak, behoort myns insiens vervang te word met 'n verwysing na kritiese denke. Die verskillende komponente van dié begrip (vaardighede, kreatiwiteit en affektiewe disposisies) behoort uitgespel te word in samehang met die oorkoepelende doelstellings van onderrig in kritiese denke by punt 4 genoem is.

Indien aanvaar word dat kritiese denke 'n opvoedkundige imperatief op tersiêre vlak is, word dit dringend noodsaaklik om veral aan die volgende probleme aandag te gee in ondersoek en debat.

* Alhoewel daar, soos hierbo opgemerk is, 'n sterk beweging is om konsensusdefinisies van 'kritiese denke', 'denkvaardighede', ensovoorts te bereik, behoort 'n debat oor die betekenisinhoud van hierdie terme aan die gang gehou te word om dogmatisme en starheid te vermy (laasgenoemde soorte houdings is kontraproduktief vir kritiese denke).

Hierdie aanhaling kom uit A. Andrews se rubriek "On Business" in die Sunday Times van 28 Februarie 1993. 
* Toetsing van denkvaardighede is 'n omstrede saak wat slegs deur verdere navorsing en debat verhelder kan word. Insette deur statistici, onderrigwetenskaplikes en sielkundiges kan hier van groot waarde wees.

* Wat is die implikasies van onderrig in kritiese denke oor die hele spektrum van die dissiplines vir kursusontwerp of kursusherontwerp en personeelopleiding? Hoe kan doserende personeel betrek word by die bevordering van kritiese denke in die verskillende dissiplines?

* Watter institusionele onderbou is nodig aan universiteite en ander tersiêre inrigtings om kritiese denke te bevorder, en hoe kan institusionele onderbou gefinansier word?

\section{Bibliografie}

FACIONE, P. 1990. Critical Thinking: A Statement of Expert Consensus for Purposes of Educational Assessment and Instruction. Millbrae : California Academic Press.

LIPMAN, M. 1989. Misconceptions in Teaching for Critical Thinking. Montclair State University : Institute for Critical Thinking. Resource Publication: Series 2 No. 3.

LYOTARD, J.F. 1984. The Postmodern Condition: A Report on Knowledge Minneapolis University of Minnesota Press.

McPECK, J. 1990. Teaching Critical Thinking. New York: Routledge

OXMAN-MICHELLI, W. 1991 (a). Critical Thinking as Mindful Learning. Montclair State University : Institute for Critical Thinking Resource Publication: Series 4 No. 1

OXMAN-MICHELLI, W. 1991 (b). Critical Thinking as Creativity. Montclair State University : Institute for Critical Thinking Resource Publication: Series 4 No. 5.

PAUL, R. 1992. Critical Thinking. What Every Person Needs to Survive in a Rapidly Changing World. Santa Rosa: Foundation for Critical Thinking

PAUL, R. \& NOSICH, G. 1991. A Proposal for the National Assessment of Higher-Order Thinking. (Paper Commissioned by The United States Department of Education.)

TOFFLER, A. 1990. Power Shift New York : Bantam Books

VAN VEUREN, P. 1991. Argumente kriteria kritiek. Pretoria : RGN. 